\title{
Shielding calculations with SCALE/MAVRIC and comparison with measurements for the TN85 cask with vitrified high level radioactive waste
}

\author{
Holger Thiele ${ }^{a}$ and Frank-Michael Börst \\ Bundesamt für Kerntechnische Entsorgungssicherheit (BfE), Willy-Brandt-Straße 5, 38226 Salzgitter, Germany
}

\begin{abstract}
A series of dose rate/spectra measurements in the German interim storage facility Gorleben was carried out at a TN85 cask in April 2009. This type of cask is used for the transport and interim storage of vitrified high level radioactive waste (HAW) from reprocessing. The aim of this work is to assess the shielding component MAVRIC of the SCALE code system with these measurements for the use in the German Bundesamt für Kerntechnische Entsorgungssicherheit (BfE).
\end{abstract}

\section{Introduction}

Aim of this paper is the presentation of the comparison of dose rates measured at a TN85 cask at the interim storage facility Gorleben with calculations.

The Bundesamt für Kerntechnische Entsorgungssicherheit (BfE) as the German competent authority for approval of design of packages for the transport of radioactive material uses the Standard Computer Analysis for Licensing Evaluation (SCALE) [1] code system developed by Oak Ridge National Laboratory (ORNL) as a calculation tool for shielding evaluation and for decision whether a new package design meets all applicable dose rate limits of the transport regulations. The main field of appclication of shielding calculations at $\mathrm{BfE}$ are thick walled metal caks.

In April 2009 radiation measurements were carried out at a TN85 cask for transport and interim storage of high level radioactive waste from reprocessing (HAW). These measurements were conducted in the interim storage facility Gorleben and included neutron and gamma dose rate measurements and spectrometric measurements for neutrons.

First results exclusively for neutron measurements were presented by Rimpler et al. at the NEUDOS-11 symposium [2].

In this paper shielding calculations for the TN85 cask are presented that were performed using the MAVRIC sequence from the SCALE system. MAVRIC calculates dose rates by performing a three-dimensional Monte-Carlo analysis (MONACO) using an automated biasing procedure. The biasing parameters are generated from results of a three-dimensional adjoint discrete ordinates calculation.

For these calculations the necessary source terms were generated with ORIGEN-ARP from the SCALE system.

\footnotetext{
${ }^{\mathrm{a}}$ Corresponding author: holger.thiele@bfe.bund.de
}

The HAW canisters as well as the basket and the cask body were modelled in detail using SCALE General Geometry Package (SGGP) geometry.

\section{Description of cask and its contents}

The TN85 casks consists of a thick-walled finned cylindrical cask body made of forged steel. In storage configuration, i.e. the configuration in which the cask has been during the measurements, the cask is closed with a primary and a secondary lid, each made of stainless steel, and their respective screws and seals. For more effective neutron shielding, chambers filled with borated resin are attached to the outside of the cask body. The same resin is used for the axial neutron shielding at the cask bottom and on the primary lid. The outer dimensions of this cask in the storage configuration as the basis for the measurements and calculations are $\sim 2.3 \mathrm{~m}$ diameter and $\sim 6 \mathrm{~m}$ in height; the loaded cask weight is $\sim 107 \mathrm{t}$. The cask is loaded with 28 HAW canisters in four levels with six canisters arranged concentrically and one central canister in each level. The general configuration of the TN85 cask is shown in Fig. 1.

The HAW canisters contain actinides and fission products in a matrix of borosilicate glass. The gamma radiation around this cask mainly results from the fission products ${ }^{134} \mathrm{Cs},{ }^{137} \mathrm{Cs}$, and ${ }^{154} \mathrm{Eu}$. Neutron radiation is mainly caused by spontaneous fission of ${ }^{244} \mathrm{Cm}$ and $(\alpha, n)$ reactions of ${ }^{244} \mathrm{Cm}$ and ${ }^{241} \mathrm{Am}$ with oxygen or boron. The average source strength ratio of spontaneous fission to $(\alpha, n)$ reactions for the calculations presented in this paper was determined with ORIGEN-ARP to be 1.3 (single standard deviation $\pm 10 \%$ ). The decay of radionuclides between time of loading and time of measurement has been taken into account. 


\section{Results of the dose rate measurements}

The dose rate measurements were carried out at a standalone TN85 cask in storage configuration at the Gorleben interim storage facility.

Commercial devices were used for measuring gamma and neutron dose rates and were calibrated according to International Commission on Radiological Protection (ICRP) Publication 60 (ICRP 60) [3]. The gamma dose rates were measured using the dosemeter $\mathrm{AD} 6$ (Automess), the neutron dose rates were measured with an LB 6411 monitor (Berthold).

The results of the measurements are plotted in Fig. 3 for gamma dose rates and in Fig. 4 for neutron dose rates.

According to manufacturer's data, the uncertainty of the gamma dose rate is $\pm 30 \%$ at maximum (relative to ${ }^{137} \mathrm{Cs}$ within an energy range from $30 \mathrm{keV}$ to $2 \mathrm{MeV}$ ). Concerning the dose rate $\dot{H}^{*}(10)$ for neutrons, the LB 6411 has an energy depending response of $\pm 40 \%$ at maximum (within an energy range from $50 \mathrm{keV}$ to $10 \mathrm{MeV}$, relating to $1 \mathrm{MeV}$ ).

At one reference position the neutron dose rate was derived from neutron spectra measured by means of a Bonner multisphere spectrometer as reference value for the evaluation of the neutron dose rates measured by commercial devices and is also shown in Fig. 4. The uncertainty of the dose rate derived with the Bonner multisphere is assessed with $\pm 15 \%$ at maximum.

\section{Modelling cask and contents}

The creation of the source terms, the modelling of the cask and its contents and finally the calculations were carried out with SCALE 6.1.3. In the MAVRIC calculation file, the geometry of the 28 HAW canisters as well as the basket and the cask body were modelled using SGGP geometry (Fig. 2). Additionally to the Safety Analysis Report [5] the "QA Life Time Records" of the TN85 cask [6] were taken into account to adapt the dimensions of the parts of the cask and its material compositions individually.

For the shielding calculations the coupled 200 neutron group - 47 gamma group library was chosen (v7-200n47g). The library is based on ENDF/B-VII data.

To obtain the gamma and neutron "ambient dose rate equivalent" $\dot{H}^{*}(10)$ according to ICRP 60 , built-in conversion coefficients based on ICRU 57 were used. They are identical to the coefficients published in ICRP Publication 74 [4].

The dose rates were calculated by placing point detectors along the $90^{\circ}$ (trunnion) and $180^{\circ}$ axis of the cask at a distance of $\sim 28 \mathrm{~cm}$ respectively $\sim 16 \mathrm{~cm}$ from the cask surface for both the gamma dose rate calculations and the neutron dose rate calculations. The chosen distance represents the distance between the measurement device and the top of the radial cooling fins of the cask.

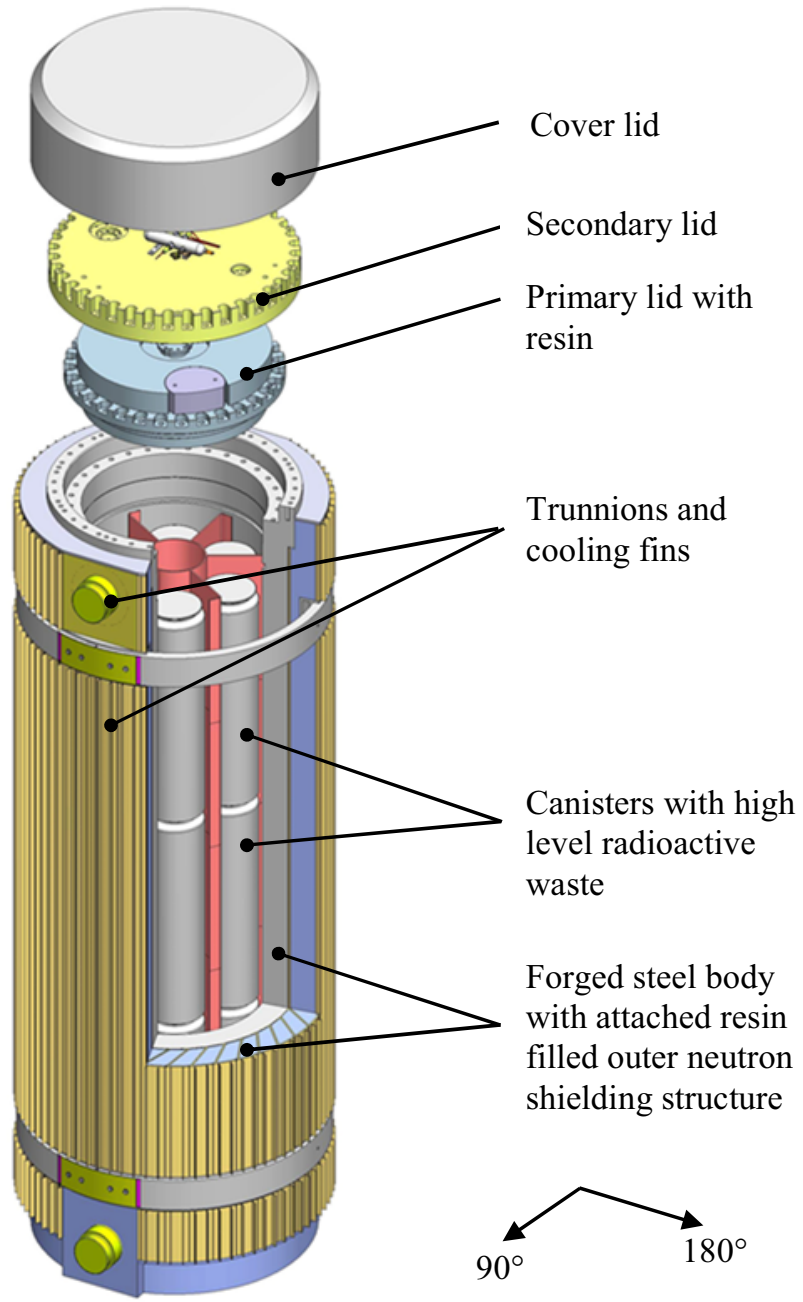

Figure 1. TN85 cask in storage configuration

The loading plan of the cask describes the content of fission products and actinides in each HAW canister with their activities and masses, respectively. For the calculations these data had to be converted into energydependent source strengths. These source strengths were obtained by decay calculations using ORIGEN-ARP software. Then, the source region was modelled with separate source strengths and spectra for each of the 28 HAW canister. The inventory that has to be considered for radiation purposes consists of six nuclides for the gamma emission $\left({ }^{90} \mathrm{Sr},{ }^{106} \mathrm{Ru},{ }^{134} \mathrm{Cs},{ }^{137} \mathrm{Cs},{ }^{144} \mathrm{Ce}\right.$, and $\left.{ }^{154} \mathrm{Eu}\right)$ and three nuclides for the neutron emission $\left({ }^{237} \mathrm{~Np},{ }^{241} \mathrm{Am}\right.$, and $\left.{ }^{244} \mathrm{Cm}\right)$.

The neutron sources induced by $(\alpha, n)$-reactions have been calculated by the use of the capabilities of ORIGEN-ARP, taking into account several target elements of the vitrified glass taken from [7]. 


\section{Results of calculation}

The results of the calculations and the measurements are shown in Fig. 3 for the gamma dose rates and in Fig. 4 for the neutron dose rates.

The standard deviations of the calculations for the gamma and neutron dose rates were about $4 \%$ and $1.5 \%$, respectively.

At the $90^{\circ}$-axis where the trunnions are located the calculated gamma dose rates are lower than the measured values, at the middle region of the cask by $49 \%$ on average (Fig. 3). For the height at $30 \mathrm{~cm}$ over ground the calculated gamma dose rate is about $22 \%$ higher than measured. One reason might be the location of the measurement devices that were not placed directly in front of the trunnion like the point tally of the calculation. Since two AD 6 were used simultaneously the positions of both devices were slightly shifted from the trunnion centre.

The neutron dose rates calculated for the middle region of the cask at the $90^{\circ}$-axis show slight deviation from the measured values of about $-19 \%$ on average (Fig. 4). Deviations that are above of the measured values for neutrons appear especially in the regions around the trunnions near the ends of the cask with up to $33 \%$ and a shifted maximum.

Compared to the dose rate measured by the Bonner sphere system at the $90^{\circ}$-axis, the results of the LB 6411 measurement and the calculations show deviations of about $-10 \%$ and $-25 \%$, respectively.

At the $180^{\circ}$-axis the differences of the measured and calculated values of the gamma and neutron dose rates for the middle region of the cask are equal to those at the $90^{\circ}$ axis. Solely at two regions around the circumferential rings which replace the radial shock absorbers during the interim storage (at heights of about $90 \mathrm{~cm}$ and $510 \mathrm{~cm}$ ) much lower neutron dose rates (by about $50 \%$ ) were calculated than measured. In opposite, at the $600 \mathrm{~cm}$ level, higher neutron dose rates have been calculated than measured.

The deviations in the calculated dose rates for regions in the vicinity of heterogeneities in the cask structure and especially in the top region may be caused by various reasons, e.g. the filling heights and composition of the contents of the canisters, uncertainties in the description of the nuclide inventory, modelling the cask structures and materials and cask surrounding structures.

Some potential sources of deviations have been quantified and examined:

The TN85 cask has not been placed in empty space. Hence, some influences of the surrounding material have to be taken into account. A plate of concrete (radius $=400 \mathrm{~cm}$, height $=20 \mathrm{~cm}$, material: "regular concrete" from the SCALE material library) has been modelled as floor structure below the cask. The possible influence has been checked by some additional calculations which do not show significant influence on the results.

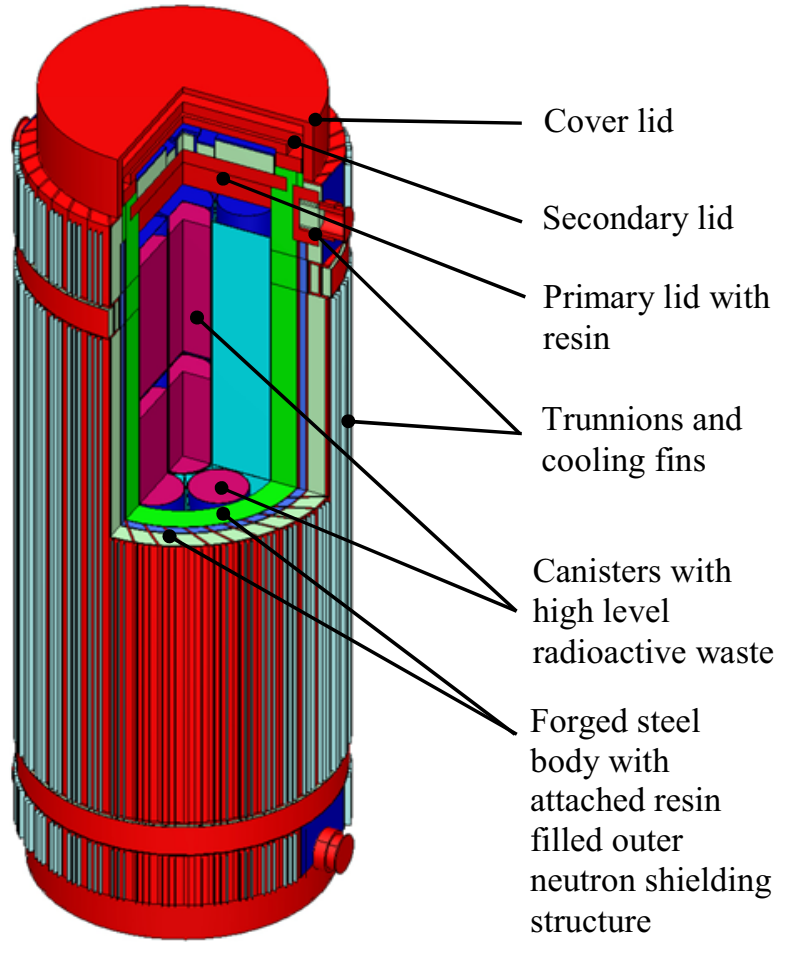

Figure 2: SGGP-Model of the TN85 cask in storage configuration

The background dose rate level during the measurements has been quantified and can also be excluded as possible source of deviations.Variations within possible parameter ranges for the density of the forged steel body (reduction of the density from $7,85 \mathrm{~g} / \mathrm{cm}^{3}$ to $7,75 \mathrm{~g} / \mathrm{cm}^{3}$ ) as well as the composition of the resin (variation of the composition) do not show any significant effect on the results.

As a further potential source of deviations a special feature of the design of the cask has been analysed. The neutron shield is the outermost shell and this causes secondary gamma radiation induced by $(n, \gamma)$-reactions with the constituents $(\mathrm{H}, \mathrm{B}, \mathrm{C}, \mathrm{O})$ of the resin. There is no significant gamma shield beyond the neutron shield. The contribution of secondary gamma radiation to the gamma dose rate is in the same order of magnitude as the primary gamma radiation therefore. Effects are discussed in section 6 . 


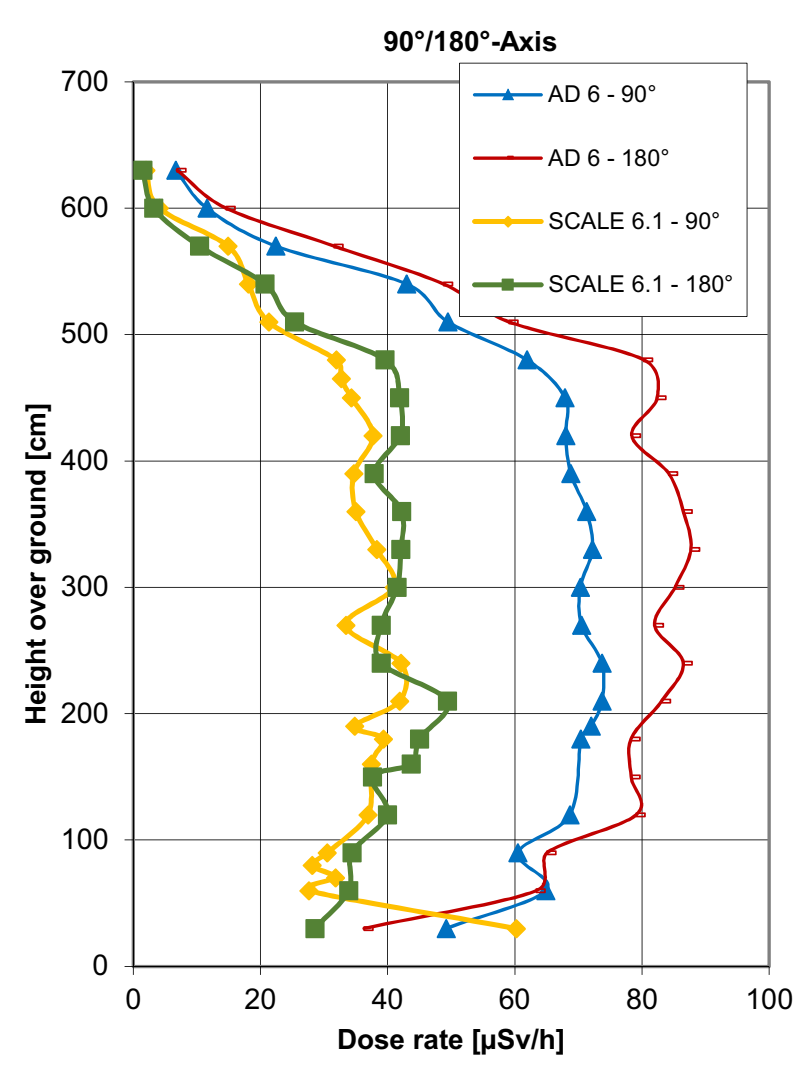

Figure 3. Gamma dose rates

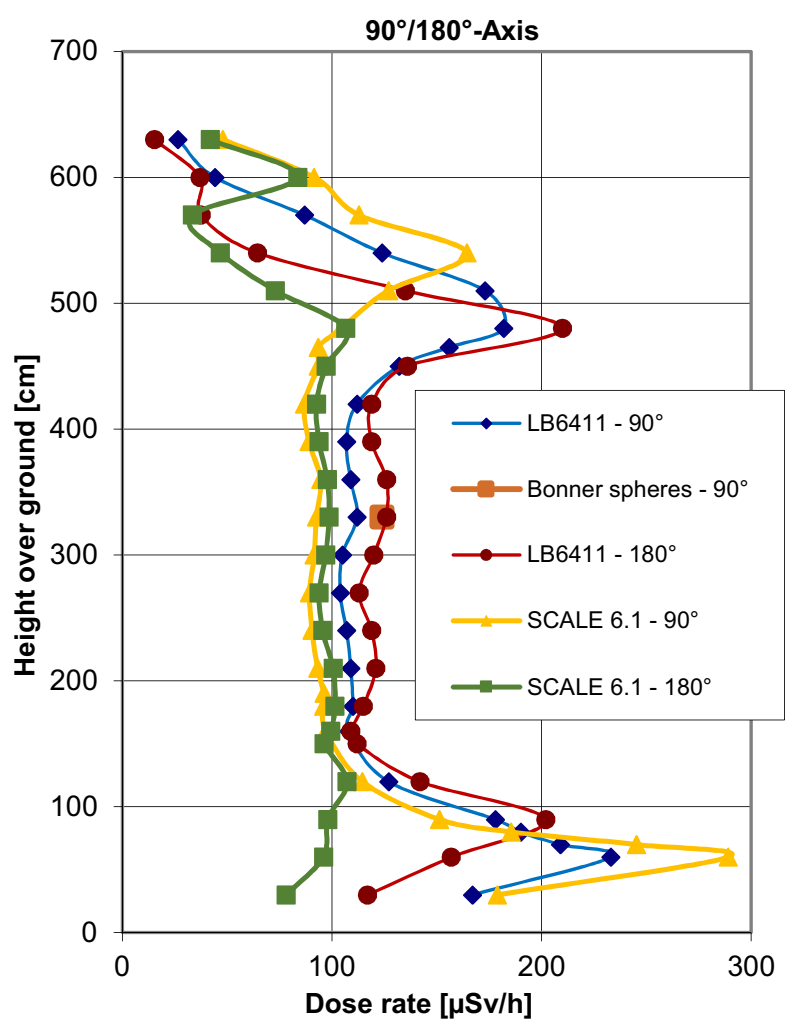

\section{Discussion and Conclusions}

The aim of this work has been to show the applicability of the shielding sequence MAVRIC of the SCALE 6.1.3 package to assess the shielding capacity of thick walled casks for HAW canisters.

The calculated dose rates are generally lower than the measured values with some exceptions. Variations in the cask model (materials, dimensions of the components) and the consideration of surrounding structures seem not to be the source of the deviations as mentioned in section 5 .

Another typical reason responsible for deviations between measured and calculated dose rates are energy dependencies of the dose rates displayed by the measurement devices, here AD 6 for gamma radiation and LB 6411 for neutron radiation.

The AD 6 has an energy dependency that shows overestimation of the dose rate for all energies above $662 \mathrm{keV}$, the energy of calibration by ${ }^{137} \mathrm{Cs}$ (Fig. 5). The energy dependence is specified up to an energy of $1.25 \mathrm{MeV}$, with a maximum overestimation by a factor of 1.35 [8]. For energies below $662 \mathrm{keV}$ the dose rate is underestimated, but in the energy range with significant photon flux at the TN85 cask, i.e. above $65 \mathrm{keV}$, the underestimation is less than $13 \%$ (Figs. 5 and 6) [8].

In the case of the TN85 cask, the energy group resolved photon flux calculated with SCALE by BfS (Fig. 6) combined with the energy dependency for the AD 6 (Fig. 5) and the fluence-to-dose conversion factors for $H^{*}(10)$ leads to a dose rate that would be displayed by an $\mathrm{AD} 6$ detector that is about $75 \%$ higher than the gamma dose rate without the energy dependency. This is an important outcome to explain the pronounced lower calculated dose rates compared to the gamma dose rates displayed by the AD 6 dosemeters. After applying an appropriate correction factor to the gamma dose rates the differences between the corrected measurement results and the results of the calculations for the majority of the calculated dose rates are about $20 \%$ and less.

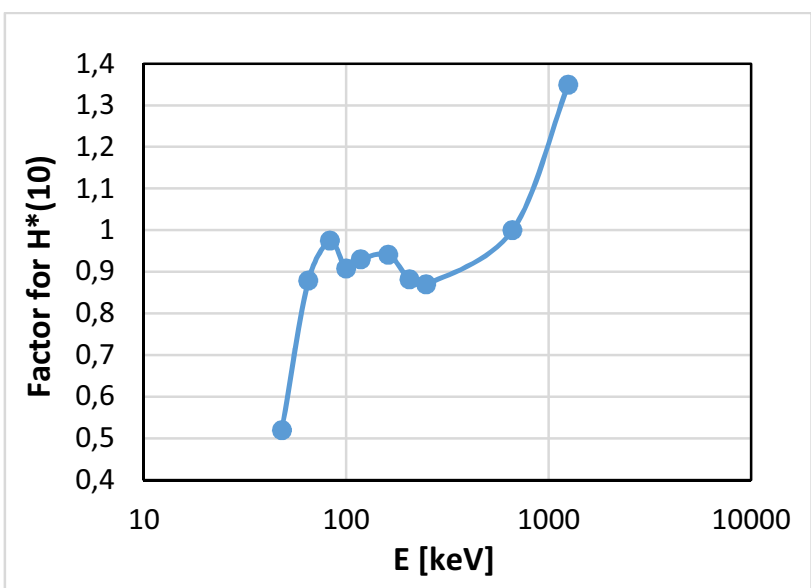

Figure 5: Energy dependency of the displayed $\dot{H}^{*}(10)$ values of the AD 6

Figure 4. Neutron dose rates 
This leads to the conclusion that even for a measurement device known to provide appropriate covering values for radiation protection purposes an analysis of the influence of the energy dependence needs to be performed when used for benchmark measurements.

The LB 6411 neutron probe has a given deviation of $\pm 40 \%$ for $\dot{H}^{*}(10)$ in the energy range between $50 \mathrm{keV}$ and $10 \mathrm{MeV}$ [9]. The majority of the calculated results is within this range of deviation.

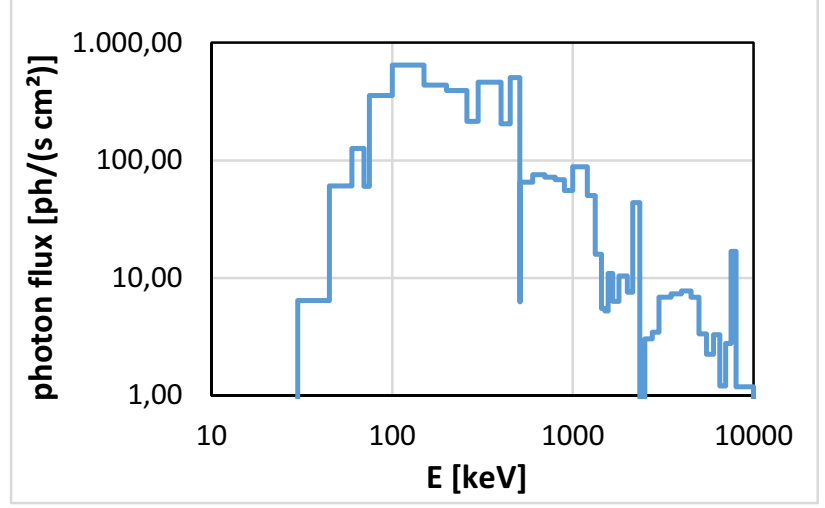

Figure 6: Energy group resolved photon flux at the cask

Furthermore, the point tallies of SCALE/MAVRIC are the standard tallies for all shielding calculations. In opposite to the point detectors of the calculations, real neutron probes have dimensions of spheres with diameters of about $30 \mathrm{~cm}$. In these cases, questions concerning geometrical influences of the probe spheres compared to point detectors and averaging effects need to be quantified.

With this in mind, the shielding sequence of the SCALE package is a suitable tool for assessing the shielding capacities of thick walled casks like the TN85.

It is planned furthermore to use the continuous energy features of the newly released SCALE 6.2 for an assessment of the included MAVRIC shielding sequence.

\section{References}

1. Scale: A Comprehensive Modeling and Simulation Suite for Nuclear Safety Analysis and Design, ORNL/TM-2005/39, Version 6.1, June 2011. Available from Radiation Safety Information Computational Center at Oak Ridge National Laboratory as CCC-785.

2. A. Rimpler, F.-M. Börst, D. Seifarth, Neutron measurements around a TN85-type storage cask with high-active waste, Radiation Measurements 45 (2010) 1290-1292.

3. "ICRP Publication 60: 1990 Recommendations of the International Commission on Radiological Protection", Ann. ICRP, Vol. 21 (No. 1-3), International Commission on Radiological Protection (1991)

4. "ICRP Publication 74: Conversion Coefficients for Use in Radiological Protection against External Radiation", Ann. ICRP, Vol. 26 (No. 3/4), International Commission on Radiological Protection (1996).
5. Safety Analysis Report for the TN85, 3644-2-Z (Rev. 8)

6. QA Life Time Records for the TN85-03 CASK, 30.10.2007

7. COGEMA Branche Retraitement (300 AQ 016), Specifications of Vitrified Residues Produced from Reprocessing at UP 2 or UP 3-A La Hague Plants, Second Series, July 1986

8. Product manual for the $6150 \mathrm{AD}^{\circledR}$ detector series, Automation und Messtechnik GmbH (automess)

9. Product manual for the LB 6411 neutron probe, BERTHOLD TECHNOLOGIES GmbH \& Co. KG 